\title{
PENJADWALAN OPERASIONAL PEMBANGKIT BERBASIS ALGORITMA GENETIK PADA SISTEM PEMBANGKIT SUMATERA BAGIAN TENGAH
}

\author{
Rahmanul Ikhsan ${ }^{1}$, Dwi Ana Ratna Wati², Budi Astuti ${ }^{3}$ \\ Jurusan Teknik Elektro, Fakultas Teknologi Industri, \\ Universitas Islam Indonesia Jalan Kaliurang Km.14,5 Sleman, Yogyakarta ${ }^{1,2,3)}$ \\ Email:dwi_ana@uii.ac.id
}

\begin{abstract}
Load demand of electric power supply varies from hour to hour in a day. It is inefficient to operate all power plants along day under various load variation. A power plant scheduling system is needed to minimize total operation cost of the power plants and in order to meet the amount of power needed by the load. This research proposes a method on power plant scheduling based on genetic algorithm. Total operation cost is used as objective function and the amount of power needed by the load is applied as a constraint. Population of chromosome in genetic algorithm represent candidates of alternative schedule of power plant operation. The best chromosome is the schedule with minimum cost and which meets the constraint. This method was applied to schedule the power plant system of Sumatera Bagian Tengah. Optimization was done in every 30 minutes. Based on test and analysis, this method results in more efficient cost, compared to manual operation of power plant systems.
\end{abstract}

Keywords : Optimasi, Penjadwalan, Algoritma Genetik.

\section{PENDAHULUAN}

Seiring dengan perkembangan di berbagai bidang kehidupan manusia, kebutuhan terhadap energi listrik terus meningkat, sehingga dibutuhkan kerja sistem kelistrikan yang andal, mulai dari sistem pembangkit, penyaluran dan beban. Dalam mencukupi kebutuhan tersebut, pembangkit mempunyai peran penting dalam penyaluran energi listrik ke konsumen. Pembangkit listrik adalah bagian dari alat industri yang dipakai untuk memproduksi dan membangkitkan tenaga listrik dari berbagai sumber tenaga.

Pada sistem pembangkit, tingkat keandalan ditentukan oleh kemampuan sistem menyuplai seluruh beban yang ada. Keandalan pembangkit merupakan probabilitas suatu alat atau pendayagunaan sistem agar mampu beroperasi pada periode tertentu sesuai dengan apa yang di harapkan Dalam melayani kebutuhan energi listrik, sistem pembangkit tenaga listrik sebaiknya dikembangkan sejalan dengan pertumbuhan pemakaian beban dengan pengkoordinasian yang baik, sehingga dapat dihindarkan adanya pemutusan aliran listrik yang diakibatkan pemakaian beban yang berlebihan.
Permintaan beban listrik selama dua puluh empat jam sehari sangat bervariasi. Pada jam - jam tertentu permintaan beban menurun, namun pada kondisi puncak permintaan beban listrik sangat tinggi. Untuk memenuhi variasi permintaan beban dan agar operasional pembangkit menjadi lebih efektif dan efisien, diperlukan adanya jadwal operasional pembangkit. Pada penelitian ini, dirancang sebuah sistem penjadwalan operasional pembangkit daerah Sumatera Bagian Tengah berdasarkan nilai permintaan beban menggunakan Algoritma Genetik. Tujuannya adalah mendapatkan jadwal operasi pembangkit yang dapat meminimalkan biaya operasional namun tetap memenuhi kebutuhan atau permintaan beban.

\section{TINJAUAN PUSTAKA \\ 2.1 Penjadwalan}

Penjadwalan adalah merupakan sebuah proses pengambilan keputusan yang sering dilakukan di industri manufaktur maupun di industri yang bergerak di bidang pelayanan atau jasa. Persoalan penjadwalan berkaitan dengan pengalokasian sumber daya ke dalam tugas - tugas atau fungsi - fungsi tertentu. Tujuan penjadwalan adalah untuk mengoptimalkan satu atau beberapa tujuan. 
Permasalahan penjadwalan merupakan permasalahan kombinatorial yang rumit karena memiliki daerah alternatif solusi yang luas dan banyak dijumpai lokal optimal. Permasalahan tersebut menjadi salah satu permasalahan penjadwalan kombinatorial yang mendapatkan banyak perhatian dari para peneliti. Beberapa diantaranya membuktikan bahwa permasalahan tersebut bertipe NP hard (non deterministic polynomial -time hard) atau tipe permasalahan yang sulit untuk diselesaikan untuk ukuran yang besar.

Penjadwalan sistem pembangkit merupakan persoalan yang harus dilakukan oleh operator sistem pembangkit setiap ada perubahan permintaan beban. Penjadwalan dilakukan dengan tujuan untuk memenuhi suplai daya ke beban dengan biaya yang minimal. Selain operasi penjadwalan secara manual, terdapat penelitian yang merekomendasikan metode untuk menjadwalkan sistem pembangkit secara otomatis misalnya penjadwalan sistem pembangkit berdasarkan incremental cost.

\subsection{Algoritma Genetik}

Algoritma genetik merupakan sebuah metode untuk menyelesaikan masalah optimasi. Algoritma ini meniru proses seleksi alam, proses yang menyebabkan evolusi biologis. Algoritma Genetik memodifikasi sebuah populasi individu yang merupakan kandidat solusi secara berulang - ulang. Dalam setiap langkah, Algoritma Genetik memilih individu - individu secara acak dari populasi untuk dijadikan induk - induk dan menggunakannya untuk menghasilkan keturunan pada generasi berikutnya.

Setelah melalui beberapa generasi, populasi berevolusi menuju kondisi solusi optimal. Algoritma Genetik dapat digunakan untuk menyelesaikan berbagai masalah optimasi yang tidak dapat diselesaikan dengan algoritma optimasi standar, termasuk masalah yang memiliki fungsi objektif yang diskontinyu, tidak dapat diturunkan, stokastik, atau tidak linier.

Proses yang terjadi pada Algoritma Genetik ditunjukkan oleh diagram alir pada gambar 1. Pada bagian awal dilakukan inisialisasi parameter Algoritma Genetik yang meliputi ukuran populasi, probabilitas crossover, probabilitas mutasi, dan jumlah generasi atau iterasi. Selanjutnya populasi kromosom yang berisi kandidat - kandidat solusi akan dibangkitkan secara acak. Setiap kromosom mewakili sebuah kandidat solusi untuk masalah optimasi yang akan diselesaikan. Kualitas kandidat solusi tersebut ditentukan oleh nilai fungsi objektif, yang mana pada algoritma genetik disebut sebagai nilai fitness. Fitness yang semakin besar mengindikasikan kualitas solusi yang lebih baik.

Tahapan selanjutnya adalah proses seleksi yaitu memilih kandidat solusi yang ada untuk melakukan proses crossover atau perkawinan silang dan mutasi atau perubahan gen. Tujuannya adalah menghasilkan kandidat solusi baru yang memiliki kualitas yang lebih baik. Dari tahapan crossover dan mutasi diperoleh generasi baru atau keturunan, yang mana kualitas dari keturunan tersebut akan dihitung berdasarkan nilai fitness.

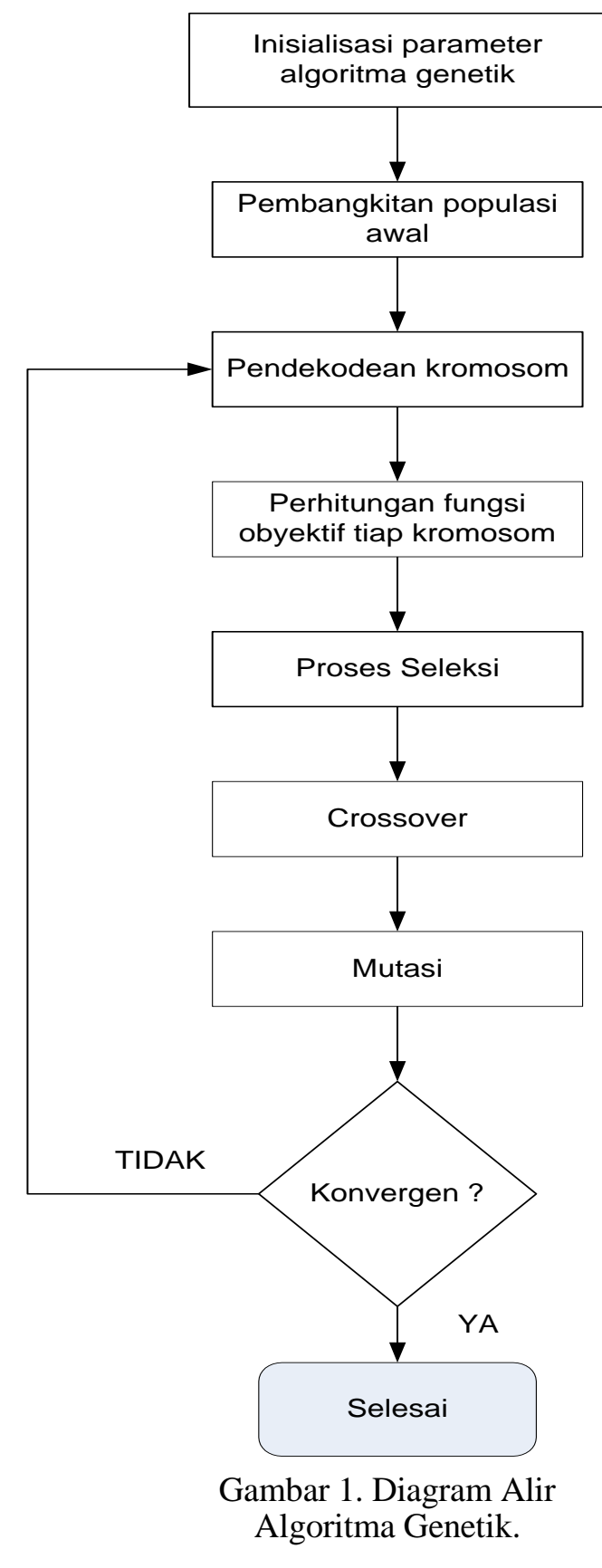




\section{PERANCANGAN SISTEM}

Pada perancangan sistem penjadwalan operasional pembangkit berdasarkan algoritma Genetik dimodelkan masalah optimasi sebagai berikut.

$$
\min f\left(x_{i}\right)
$$$$
\text { subject to } T P\left(x_{i}\right) \geq T P D \text {. }
$$

dengan $x_{i}$ bernilai 0 atau 1 dan $i=1,2,3 \ldots, n$ yang mana $n$ adalah banyaknya pembangkit yang dimiliki oleh sistem pembangkit, dalam hal ini pada sistem pembangkit Sumatera Bagian Tengah terdapat 46 unit pembangkit dan sebuah catu transfer dari daerah lain. $x_{i}$ bernilai 0 atau 1 mewakili kondisi pembangkit 0 artinya nol pembangkit tidak aktif dan 1 artinya pembangkit aktif atau beroperasi. $f\left(x_{i}\right)$ adalah total biaya yang harus dikeluarkan untuk setiap mengoperasikan pembangkit, yang dirumuskan sebagai berikut :

$$
f\left(x_{i}\right)=\sum_{i=1}^{n} x_{i} C_{i} P_{i}
$$

yang mana $\mathrm{C}_{\mathrm{i}}$ adalah biaya yang harus dikeluarkan untuk menghasilkan daya per Watt pada pembangkit ke- $i$, dan $\mathrm{P}_{\mathrm{i}}$ adalah daya total yang dihasilkan oleh pembangkit ke- $i$, dengan asumsi tidak ada rugi - rugi daya. Batasan atau constraint yang digunakan adalah $T P\left(x_{i}\right)$ yaitu daya total yang dihasilkan sistem pembangkit yang aktif harus lebih besar atau sama dengan TPD yaitu total daya yang diminta oleh beban.

Untuk menyelesaikan masalah optimasi di atas, digunakan Algoritma Genetik dengan pengkodean kromosom (gambar 2) berupa nilai 0 atau 1 yang mewakili variabel $x_{i}$ yaitu kondisi apakah sebuah pembangkit aktif atau tidak aktif. Jadi satu gen mewakili kondisi sebuah pembangkit.

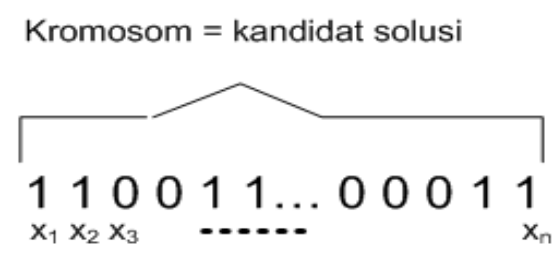

Gambar 2. Representasi Kromosom.
Algoritma Genetik merupakan algoritma optimasi yang bekerja untuk mencari nilai maksimum yang direpresentasikan dalam nilai fitness. Sedangkan persoalan penjadwalan sistem pembangkit ini bertujuan untuk mencari nilai minimum dari biaya operasional pembangkit. Untuk itu agar persoalan penjadwalan pembangkit ini dapat diselesaikan dengan metode Algoritma Genetik, perlu dilakukan perubahan fungsi biaya atau cost menjadi fungsi fitness. Pada penelitian ini digunakan persamaan untuk membentuk fungsi fitness sebagai berikut :

$f i t(i)=\frac{1}{f\left(x_{i}\right)+z_{i}}$

Mekanisme penanganan batasan atau constraint pada kasus ini menggunakan teknik pinalti, yaitu sebuah kandidat solusi akan dicek terlebih dahulu apakah memenuhi syarat yang ada pada batasan, yaitu total daya yang dihasilkan harus lebih besar dari daya yang diminta beban. Jika memenuhi syarat tersebut maka akan dihitung nilai biaya atau cost dari kandidat solusi tersebut. Sebaliknya jika syarat tersebut tidak terpenuhi, maka kandidat solusi tersebut akan diberi pinalti berupa pinalti linier yang dihitung berdasarkan nilai daya yang dihasilkan oleh kandidat solusi tersebut yang dirumuskan sebagaimana pada persamaan (4). Mekanisme pinalti dan perhitungan fitness digambarkan pada diagram alir pada gambar 3 .

$$
p\left(x_{i}\right)=\sum_{i=1}^{n} x_{i} P_{i}-T P D
$$

Dari individu - individu yang ada dalam suatu populasi, perlu dipilih individu individu terbaik yang dapat melakukan perkawinan untuk menghasilkan individu baru. Masing - masing individu dalam populasi akan menerima probabilitas reproduksi sebanding dengan nilai fitnessnya.

Proses seleksi dilakukan berdasarkan prinsip fitness rangking menggunakan nilai probabilitas yang dihitung berdasarkan nilai fitness setiap kromosom. Semakin tinggi nilai fitness, semakin besar peluang sebuah kromosom untuk terpilih sebagai induk pada proses pindah silang maupun mutasi untuk menghasilkan keturunan. 


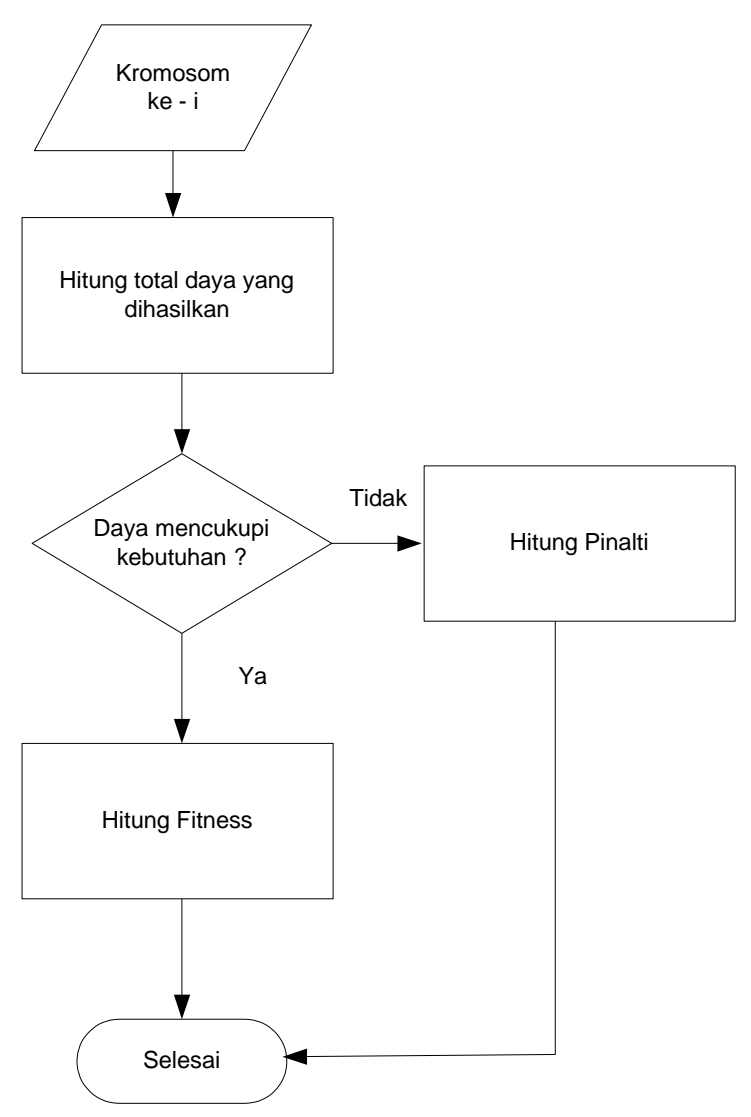

Gambar 3. Mekanisme Pinalti.

\section{ANALISA DAN PEMBAHASAN}

Algoritma Genetik yang telah dirancang untuk melakukan penjadwalan sistem pembangkit Sumatera Bagian Tengah selanjutnya diuji dengan simulasi. Pengujian optimasi penjadwalan dilakukan dengan periode setiap 30 menit dalam satu hari selama 24 jam sesuai dengan operasi penjadwalan manual yang biasa dilakukan pada sistem pembangkit di daerah tersebut. Hasil pengujian optimasi penjadwalan pembangkit diperoleh penjadwalan setiap unit pembangkit, besar beban yang dibangkitkan dan biaya operasional dari unit pembangkit yang diaktifkan.

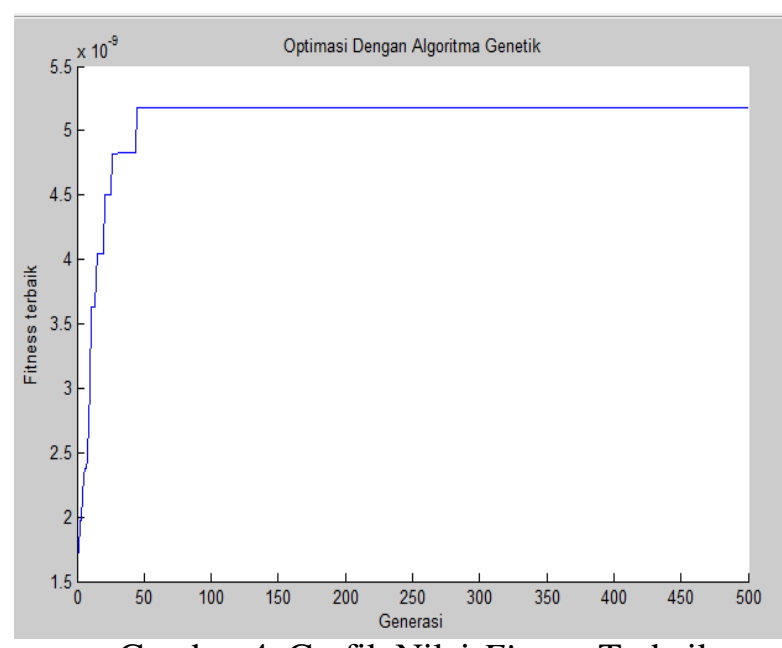

Gambar 4. Grafik Nilai Fitness Terbaik Selama Iterasi

Sebagai contoh pengujian, dilakukan penjadwalan pembangkit pada pukul $01: 00$ dengan permintaan beban sebesar 695.200 KWh. Grafik fungsi fitness proses optimasi penjadwalan tersebut ditunjukkan pada gambar 4 dan hasil optimasi berupa pembangkit yang diaktifkan dirangkum pada tabel 1, dengan biaya operasional $\mathrm{Rp}$. 193.135.740, dan total daya yang dibangkitkan 696.100 KWh. Sedangkan operasi secara manual (PLN) mengaktifkan pembangkit dengan total daya 838.870 KWh dan biaya operasional sebesar Rp. 1.653.537.169,20. Hal ini menunjukkan hasil penjadwalan dengan teknik optimasi berbasis Algoritma Genetik mampu menghemat daya sebesar 142,77 KWh dan tentunya juga menghemat biaya.

Tabel 1. Contoh Hasil Optimasi.

\begin{tabular}{|c|c|c|}
\hline & \multicolumn{2}{|c|}{$\begin{array}{c}\text { PEMBANGKIT } \\
\text { AKTIF }\end{array}$} \\
& $\begin{array}{l}\text { 0 : Tidak Aktif } \\
\text { 1: Aktif }\end{array}$ \\
\cline { 2 - 3 } NAMA PEMBANGKIT & PLN & GA \\
\hline PLTA MNJAU \#4 & $\mathbf{0}$ & $\mathbf{1}$ \\
PLTA BTGAM \#1 & $\mathbf{0}$ & $\mathbf{1}$ \\
PLTA BTGAM \#2 & $\mathbf{1}$ & $\mathbf{0}$ \\
PLTA BTGAM \#3 & $\mathbf{1}$ & $\mathbf{1}$ \\
PLTA KTPJG \#1 & $\mathbf{1}$ & $\mathbf{1}$ \\
PLTA KTPJG \#2 & $\mathbf{1}$ & $\mathbf{1}$ \\
PLTA KTPJG \#3 & $\mathbf{0}$ & $\mathbf{1}$ \\
PLTG PLIMO \#1 & $\mathbf{0}$ & $\mathbf{0}$ \\
PLTG PLIMO \#2 & $\mathbf{1}$ & $\mathbf{0}$ \\
PLTG PLIMO \#3 & $\mathbf{1}$ & $\mathbf{0}$ \\
PLTU OMBLN \#1 & $\mathbf{1}$ & $\mathbf{1}$ \\
PLTU OMBLN \#2 & $\mathbf{1}$ & $\mathbf{1}$ \\
PLTG TLMBU \#1 & $\mathbf{0}$ & $\mathbf{0}$ \\
PLTG TLMBU \#2 & $\mathbf{0}$ & $\mathbf{0}$ \\
\hline
\end{tabular}




\begin{tabular}{|c|c|c|}
\hline PLTG TLMBU \#3 & 0 & 0 \\
\hline PLTD TLMBU & 0 & 0 \\
\hline PLTG BTHRI \#2 & 1 & 1 \\
\hline PLTG BTHRI \#3 & 1 & 0 \\
\hline $\begin{array}{c}\text { PLTD SEWA RIAU } \\
\text { AGREKO }\end{array}$ & 1 & 0 \\
\hline PLTD SEWA & 1 & 0 \\
\hline PURNAMA DUMAI \#1 & 1 & 0 \\
\hline $\begin{array}{c}\text { PLTD SEWA } \\
\text { PURNAMA DUMAI \#2 }\end{array}$ & 1 & 0 \\
\hline PLTD SEWATAMA & 1 & 0 \\
\hline $\begin{array}{l}\text { PLTMG SUNGAI } \\
\text { GELAM \#1 }\end{array}$ & 1 & 0 \\
\hline PLTG DURI \#1 & 0 & 0 \\
\hline PLTG DURI \#2 & 0 & 0 \\
\hline PLTG PYCAH \#1 & 0 & 1 \\
\hline $\begin{array}{l}\text { PLTG PYCAH \#2 } \\
\text { PLTD SEWA }\end{array}$ & 0 & 1 \\
\hline $\begin{array}{c}\text { SUMBAR AGEREKO } \\
\# 1\end{array}$ & 1 & 0 \\
\hline PLTD SEWA & & \\
\hline $\begin{array}{c}\text { SUMBAR AGEREKO } \\
\# 2 \\
\text { PLTD SEWA }\end{array}$ & 1 & 0 \\
\hline $\begin{array}{c}\text { SUMBAR AGEREKO } \\
\# 3 \\
\text { PLTD SEWA }\end{array}$ & 1 & 0 \\
\hline $\begin{array}{c}\text { SUMBAR AGEREKO } \\
\# 4\end{array}$ & 1 & 0 \\
\hline $\begin{array}{l}\text { PLTG RPWER } \\
\text { TRANSFER }\end{array}$ & $\begin{array}{l}0 \\
1\end{array}$ & $\begin{array}{l}0 \\
0\end{array}$ \\
\hline
\end{tabular}

GRAFIKPERBANDINGANDAFA (KWH)

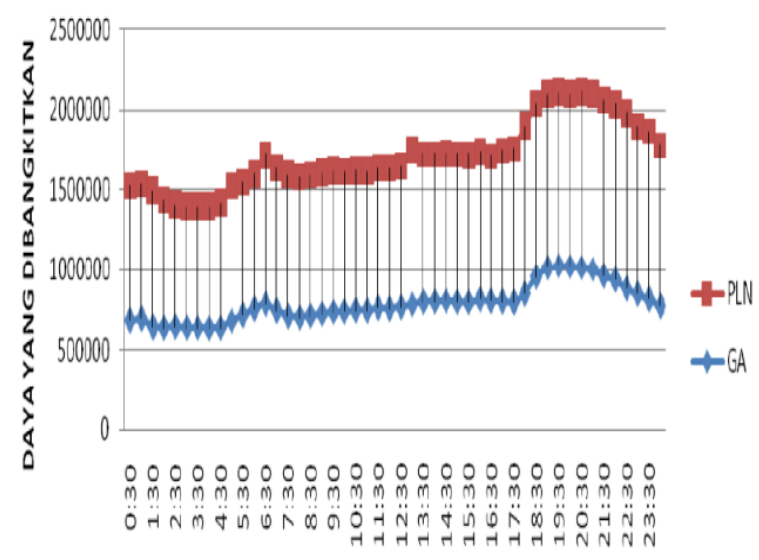

PUKUL

Gambar 5. Grafik Perbandingan Daya Antara Hasil Penjadwalan dengan Algoritma Genetik dan Penjadwalan Manual (PLN).

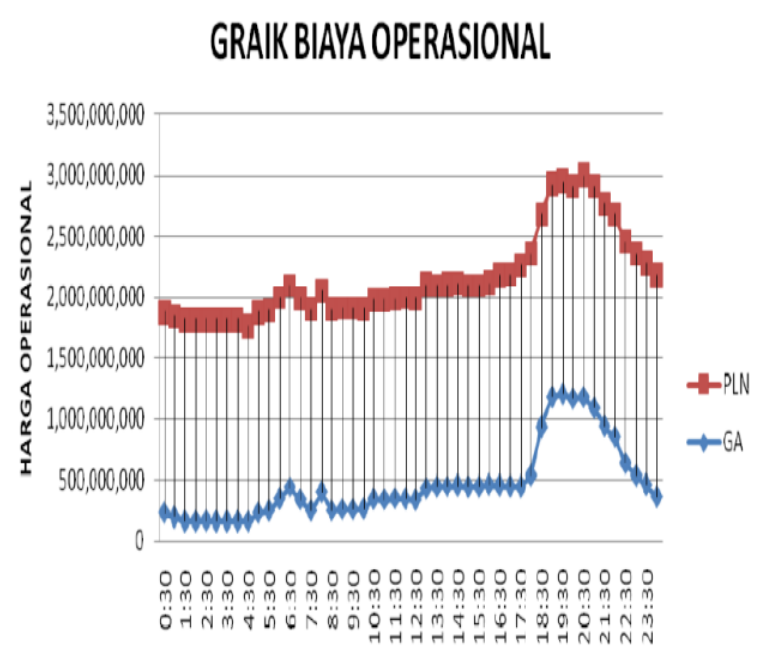

PUKUL

Gambar 6. Grafik Perbandingan Daya Antara Hasil Penjadwalan dengan Algoritma Genetik dan Penjadwalan Manual (PLN).

Secara keseluruhan hasil penjadwalan secara otomatis selama 24 jam menggunakan Algoritma Genetik menghasilkan grafik perbandingan daya pada gambar 4 dan grafik perbandingan biaya operasional pada gambar 5. Dari hasil perbandingan diperoleh bahwa terjadi penghematan daya rata - rata sekitar $46 \%$ dan penghematan biaya operasional rata - rata sekitar $70 \%$. Hal ini terjadi karena pada operasi manual selalu menggunakan daya transfer dari daerah lain yang mana daya transfer tersebut mempunyai biaya yang jauh lebih mahal.

\section{KESIMPULAN}

Pada penelitian ini telah dirancang sebuah sistem penjadwalan pembangkit menggunakan Algoritma Genetik. Berdasarkan hasil pengujian dan analisisnya, dapat disimpulkan bahwa metode penjadwalan pembangkit dengan metode Algoritma Genetik dapat menghasilkan jadwal operasional pembangkit yang mampu meminimalkan biaya operasional sistem pembangkit dan tetap menjaga agar kebutuhan atau permintaan beban dapat dipenuhi, sehingga menghindarkan kejadian pemadaman listrik. 
Penjadwalan yang dilakukan pada penelitian ini masih sebatas simulasi berdasarkan data riil yang diambil sebelumnya. Oleh karena itu, selanjutnya metode ini sebaiknya diuji dengan diterapkan secara langsung pada sistem pembangkit Sumatera Bagian Tengah agar dapat diperoleh data hasil implementasi riil dan digunakan untuk perbaikan metode serta dapat juga diuji untuk digunakan pada sistem pembangkit di daerah yang lain.

\section{DAFTAR PUSTAKA}

Aldasht,M.M., Saheb,M., Najjar, Tamimi, M.H., Takruri, T.O. (2005). University Course Scheduling Using Parallel Multi-Objective Evolutionary Algorithms. Journal of Theoretical and Applied Information Technology, www.jatit.org .

Amirthagadeswaran, K. S. , Arunachalam, V. P.,. (2006). Improved solutions for job shop scheduling problems through genetic algorithm with a different method of schedule deduction. International Journal of Advanced Manufacturing Technology.

Haupt, R.L., Haupt, S.E. (2004). Practical Genetic Algorithm, Second Edition. Wiley, Second Edition.

Imran, A, 2008, Optimasi Penjadwalan Pembangkitan Di Antara Unit Unit Pembangkit Termal Berdasarkan Incremental Production Cost Yang Sama, Media Elektrik Volume 3, Nomor 2, 2008 hal 130-135.

Marsudi, D, (2006), Operasi Sistem Tenaga Listrik, Jakarta, Graha Ilmu.

Pinedo, M. L. (2012). Scheduling: Theory, Algorithms, and Systems. New York : Springer.

Xia, W., Wu, Z. (2006). A hybrid particle swarm optimization approach for the job-shop scheduling problem. International Journal of Advanced Manufacturing Technology , $360-$ 366.
$\mathrm{Yu}$, J. (2006). Scheduling of an assembly line with a multi-objective genetic algorithm. International Journal of Advanced Manufacturing Technology. 